\title{
Acceptability and practicability of self- management for patients with Parkinson's disease based on smartphone applications in China
}

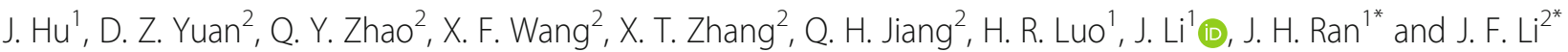

\begin{abstract}
Background: China has had about 1.2 billion mobile-phone users, and this number continues to grow. However, mobile-health services (mHealth) are currently in the initial stage, and have not yet prevailed in China. Additionally, the prevalence of Parkinson's disease (PD) in China is 1700/100,000 ( $\geq 65$ years). Indeed, these PD patients would benefit from mHealth to manage their disease. Therefore, we designed a study to determine attitudes toward smartphone applications (apps) for chronic condition self-management, and to discover the practicality of these apps among PD patients in China.

Methods: We selected 204 participants with PD between 52 and 87 years old and surveyed their attitudes concerning the use of smartphone apps for chronic condition management via questionnaires.

Results: Among the participants, 65.19\% had smartphones. Among these smartphone users, $82.84 \%$ expressed a preference for using apps for PD management. This group tended to be younger and more frequent web users with higher education and better medication compliance, and they tended to have a longer PD course and worse conditions $(P<0.001, P=0.001, P<0.001, P=0.041, P<0.001, P=0.013)$. Additionally, the willingness to apply apps for PD self-management was positively related to education $(P<0.001)$ and negatively related to age and PD course $(P=0.017, P<0.001)$.

Conclusion: In China, patients with PD have a generally positive attitude towards self-management through smartphone apps. Consequently, improving the coverage of smartphones with practical and handy apps is a promising strategy for PD self-management.
\end{abstract}

Keywords: Parkinson's disease, Smartphone apps, Chronic management, mHealth

\section{Background}

Parkinson's disease (PD) is a progressive neurological disorder associated with the degeneration of dopamineproducing cells in the nigra [1]. Up to now, the average

\footnotetext{
* Correspondence: ranjianhua@cqmu.edu.cn; lijinfang@hospital.camu.edu.cn 'Department of Anatomy, and Laboratory of Neuroscience and Tissue Engineering, Basic Medical College, Chongqing Medical University, No.1, Yixueyuan Road, Chongqing 400010, China

${ }^{2}$ Department of Neurology, the Second Affiliated Hospital of Chongqing Medical University, No.76, Linjiang Road, Chongqing 400010, China
}

prevalence and incidence of Parkinson's disease (PD) in China have been $1700 / 100,000$ ( $\geq 65$ years) and 797/100, 000 (per year) respectively, also, the number of PD prevalence is expected to reach about 5 million by 2030 [2-4]. The cardinal features of PD are bradykinesia, tremors, rigidity, and postural instability [5]. Patients suffering from PD are frequently disturbed by the motor symptoms of PD in daily functions, activities, and roles [6]. Although the pathological mechanism and treatment

(c) The Author(s). 2020 Open Access This article is licensed under a Creative Commons Attribution 4.0 International License, which permits use, sharing, adaptation, distribution and reproduction in any medium or format, as long as you give appropriate credit to the original author(s) and the source, provide a link to the Creative Commons licence, and indicate if changes were made. The images or other third party material in this article are included in the article's Creative Commons licence, unless indicated otherwise in a credit line to the material. If material is not included in the article's Creative Commons licence and your intended use is not permitted by statutory regulation or exceeds the permitted use, you will need to obtain permission directly from the copyright holder. To view a copy of this licence, visit http://creativecommons.org/licenses/by/4.0/. The Creative Commons Public Domain Dedication waiver (http://creativecommons.org/publicdomain/zero/1.0/) applies to the data made available in this article, unless otherwise stated in a credit line to the data. 
strategy of PD have progressed significantly in recent years, there is still no effective treatment strategy. Recent studies have indicated that smartphone applications (apps) have the potential to offer automated and customized support for medication compliance to individuals with chronic diseases [7]. Recently, a variety of apps have been developed and successfully applied for effective self-management by patients with hypertension, diabetes, and other chronic diseases [8-12]. Moreover, apps for PD self-management have been used in countries such as the Netherlands and Sweden [13, 14]. Indeed, self-management is considered one of the most effective measures to help improve PD patient medication compliance, control their clinical symptoms, and mitigate the adverse effects of the disease [13, 15].

China has about 1.2 billion cell-phone users, and this number continues to grow [16]. However, mobile health services (mHealth) are currently in their initial stages. The key to the success of any app is to cater to the willingness of the targeted individuals and to secure their acceptance, while facilitating their use of the technology $[17,18]$. Thus, the purpose of our research was to investigate the acceptability and practicability of using apps for PD self-management in China.

\section{Methods}

\section{Subjects and interviews}

All PD patients were recruited from the Parkinson's Clinic at the Second Affiliated Hospital of Chongqing Medical University. The patients were examined by at least two experienced neurologists. In our study, PD was determined according to the diagnosis of PD and exclusionary criteria [19]. All participants were able to read, write, and understand what they were asked, ensuring their ability to complete the questionnaire. The investigators were trained rigorously in the methodology of the study before interviewing the target patients. This study was approved by the Research Ethics Committee of the Second Affiliated Hospital. All patients signed an informed consent form when enrolling in the study.

\section{Questionnaire content}

The questionnaire (Supplementary file) consisted of Part I, Part II, Part III, and Part IV. Part I pertained to patient characteristics, including demographic data (age, gender, educational level, occupation) and the main clinical features of PD (PD disease course, number of anti-PD drugs, Movement Disorder Society Unified Parkinson's Disease Rating Scale (MDS-UPDRS) [20], and Hoehn \& Yahr Stage (H \& Y) [21]).

Part II surveyed the number of patients with mobile phones and the ways they used them to obtain general information about PD. We also investigated the preferences of patients with PD with regards to smartphone apps. According to this survey, PD patients used smartphones to seek general information about PD (symptoms, pathophysiology, epidemiology, and prognosis), to interact with doctors and ask them questions, for advice about medication types, new medicines, side effects, and symptoms, for videos and written information on the motor and non-motor symptoms of PD, for suitable rehabilitation exercises, and for adverse factors to be avoided, such as missing medication, accidental falls, emotional disorders, and sleep deprivation.

Part III evaluated medication adherence. A modified Morisky Medication Adherence Scale (MMAS-8) was used. MMAS- 8 offers good test-retest reliability (intraclass correlation coefficient $=0.729$ ) and moderate internal consistency (Cronbach's $\alpha=0.556$ ) [22-24]. Seven of the eight items (Items 1-7) were yes/no questions, where "no" was given one point, and "yes" received zero points. Item 8 was measured on a five-point Likert scale, in which "never," "once in a while," "sometimes," "usually," and "all the time" were respectively scored at 1 , $0.75,0.50,0.25$, and 0 [22-25].

Part IV was a questionnaire with ten items designed to assess attitudes toward apps for self-managing PD. These items were all answered using a five-point Likert type scale: strongly agree (5), agree (4), neutral (3), disagree (2), and strongly disagree (1). The questionnaire was an improved version of questionnaires used in the studies on the use of apps for chronic disease management in patients with epilepsy and asthma [26, 27].

\section{Statistical analysis}

SPSS 25.0 and Graphpad Prism 7.0 software was used for statistical analysis. The demographics and clinical characteristics of the patients were analyzed according to the mean \pm standard deviation (SD) for continuous variables and by frequency distributions for categorical variables. Attitudes toward smartphones were analyzed using the Student's $t$-test for continuous variables, Pearson chi-squared test for categorical variables, and Spearman correlation analysis.

\section{Results}

\section{Demographics and clinical characteristics}

Between January 2017 and May 2018, a total of 208 patients were asked to participate in the survey. Of these, 204 participants (115 male and 89 female) agreed. The average age of the participants was $68.75 \pm 9.54$ years, ranging from 52 to 87 years old. The number of patients who lived in cities and rural areas was $172(84.31 \%)$ and $32(15.69 \%)$, respectively. The mean education level of the participants was $5.20 \pm 3.14$ years (from 1 year to 15 years). In addition, $71.08 \%$ of patients took no more than two types of anti-PD drugs. The mean Morisky Scale 
score was $5.75 \pm 1.45$. The demographic details of the patients are given in Table 1.

\section{Mobile phone usage and means of obtaining PD information}

Almost all respondents (96.08\%, 196/204) owned cell phones, and most patients (65.19\%, 133/204) owned smartphones or had access to them. According to our survey, $50.00 \%(102 / 204)$ of patients browsed the web; $20.59 \%(21 / 102)$ of these used computers to do so, while $79.41 \% \quad(81 / 102)$ used smartphones. Respondents claimed they obtained PD information from doctors in clinics (100\%, 204/204), from smartphones (15.20\%, 31/ 204), and through other media $(7.43 \%, 16 / 204)$ (Fig. 1).

\section{Willingness and attitude toward PD self-management apps}

Only $8.82 \%$ (18/204) of participants had heard of apps for managing chronic diseases such as diabetes mellitus

Table 1 Demographic and Parkinson's disease-related clinical characteristics of surveyed participants

\begin{tabular}{|c|c|c|}
\hline Variable & No. & $\%$ \\
\hline \multicolumn{3}{|l|}{ Age (years) } \\
\hline$\leq 60$ & 46 & 22.55 \\
\hline $61-70$ & 84 & 41.76 \\
\hline$\geq 71$ & 74 & 36.27 \\
\hline \multicolumn{3}{|l|}{ Gender } \\
\hline Male & 115 & 56.37 \\
\hline Female & 89 & 43.63 \\
\hline \multicolumn{3}{|l|}{ Resident location } \\
\hline Urban & 172 & 84.31 \\
\hline Rural & 32 & 15.69 \\
\hline \multicolumn{3}{|l|}{ Education level } \\
\hline$\leq 6$ & 39 & 19.12 \\
\hline $7-12$ & 127 & 62.25 \\
\hline$\geq 13$ & 38 & 18.63 \\
\hline \multicolumn{3}{|l|}{ Occupation (employment) } \\
\hline self-employed & 32 & 15.69 \\
\hline Stable work or retirees & 172 & 84.31 \\
\hline \multicolumn{3}{|l|}{ Number of anti-PD drug } \\
\hline$\leq$ two drugs & 145 & 71.08 \\
\hline$\geq$ three drugs & 59 & 28.92 \\
\hline \multicolumn{3}{|l|}{ PD course } \\
\hline$\leq 5$ & 133 & 65.20 \\
\hline$\geq 6$ & 71 & 34.80 \\
\hline \multicolumn{3}{|c|}{ MDS-UPDRS (Hoehn \& Yahr Grade) } \\
\hline$\leq 50(\mid \sim \|)$ & 115 & 56.37 \\
\hline $51-100(I I I)$ & 89 & 43.63 \\
\hline
\end{tabular}

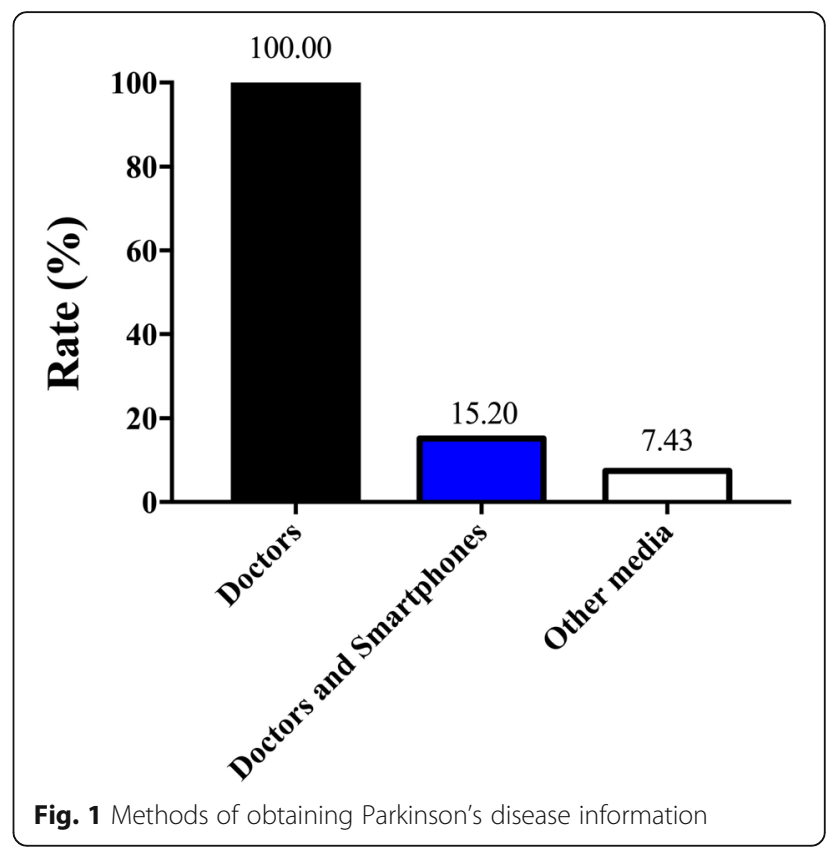

or hypertension. However, more than half of the surveyed patients indicated that they would use apps for PD self-management given the following: the apps are provided for free and are useful and easy to operate; the apps can be used to remind the user to take medication on time; the user's privacy is protected; and the apps reduce economic and psychological burden (Table 2). Most importantly, the participants had a positive attitude toward using PD self-management apps, provided that the apps are easy to operate.

\section{Participant interest in smartphone app content for PD management}

The interest of the participants in various content on smartphone apps for PD self-management is depicted in Fig. 2. The percentage of patients interested in general PD information, interacting with doctors online, medication advice, recording symptoms, and PD education was $60.29,77.46,54.90,65.69$, and $80.88 \%$, respectively.

\section{Characteristics of respondents with positive attitudes to using apps}

To better understand the characteristics of potential users, we analyzed the correlation between each item related to patient attitudes toward smartphone apps. In particular, we measured the survey item, "I would try it out, if it were easy to operate." This item reflects a key point concerning patient benefits. The demographic and clinical characteristics of the participants are shown in Table 3. Among these patients, those who tended to use apps were younger and better educated, they had good medication adherence, they tended to browse the web, 
Table 2 Survey results of reaction to the Parkinson disease management apps for related patients

\begin{tabular}{|c|c|c|c|}
\hline Survey items & $\begin{array}{l}S A+A \\
N(\%)\end{array}$ & $\begin{array}{l}\mathrm{N} \\
\mathrm{N}(\%)\end{array}$ & $\begin{array}{l}\mathrm{SDA}+\mathrm{DA} \\
\mathrm{N}(\%)\end{array}$ \\
\hline \multirow[t]{2}{*}{ I would use it, if it were free. } & 136 & 47 & 21 \\
\hline & 66.67 & 23.04 & 10.29 \\
\hline \multirow[t]{2}{*}{ I would try it out, if it were easy to operate. } & 169 & 20 & 15 \\
\hline & 82.84 & 9.81 & 7.35 \\
\hline \multirow[t]{2}{*}{ I would use it, if it allowed doctor to make medication change quicker. } & 145 & 41 & 18 \\
\hline & 71.09 & 20.09 & 8.82 \\
\hline \multirow[t]{2}{*}{ I would use it, if it protected my privacy. } & 139 & 22 & 43 \\
\hline & 68.14 & 10.78 & 21.08 \\
\hline \multirow[t]{2}{*}{ I think it will solve the questions related to Parkinson's disease. } & 124 & 66 & 14 \\
\hline & 60.78 & 32.35 & 6.86 \\
\hline \multirow[t]{2}{*}{ I think it will help remind me to follow doctors' directions. } & 150 & 32 & 22 \\
\hline & 73.53 & 15.69 & 10.78 \\
\hline \multirow[t]{2}{*}{ I think it will reduce the psychological burden of Parkinson's disease. } & 160 & 26 & 23 \\
\hline & 75.98 & 12.75 & 11.27 \\
\hline \multirow[t]{2}{*}{ I think it will reduce the frequency of seeking medical advice and the costs. } & 148 & 37 & 19 \\
\hline & 72.55 & 18.14 & 9.31 \\
\hline \multirow[t]{2}{*}{ I believe it well be helpful for me to communicate with doctor. } & 151 & 18 & 37 \\
\hline & 73.04 & 8.82 & 18.14 \\
\hline \multirow[t]{2}{*}{ I think it will be useful to manage my Parkinson's disease. } & 141 & 63 & 3 \\
\hline & 67.65 & 30.88 & 1.47 \\
\hline
\end{tabular}

SA strongly agree, $A$ agree, $N$ neutral, SDA strongly disagree, $D$ disagree, $S D$ standard deviation

and they had a longer PD course with worse PD conditions $(P<0.001, P=0.001, P<0.001, P=0.041, P<0.001$, $P=0.01)$. In regard to willingness to use apps, there were no statistically differences between women and men $(P=0.517)$, resident location (urban or rural, $P=0.795)$,

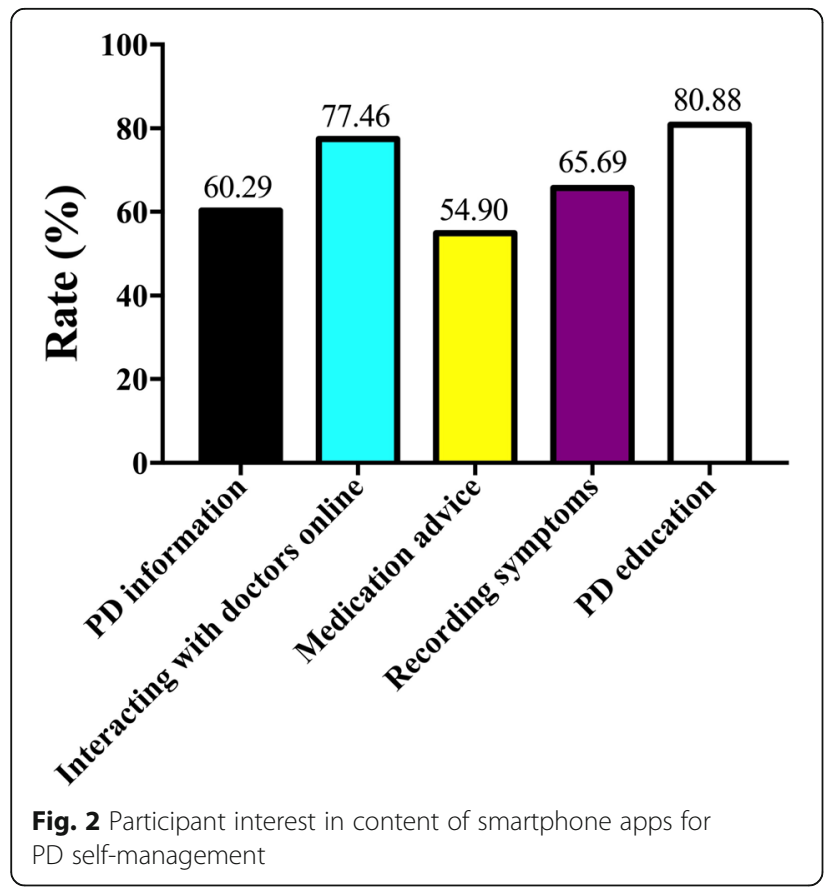
occupation (self-employed or stable work/retired, $P=$ 0.478 ), or drug intake number (no more than two or no fewer than three anti-PD drugs, $P=0.162$ ).

To further investigate the correlation between the characteristics of the participants and PD app acceptance, we performed a correlation analysis. The results suggest that the willingness of patients to use apps for PD management is positively related to education level $(P<0.001)$. However, the age and PD course were negatively correlated with it $(P=0.017, P<0.001)$, and MDSUPDRS was uncorrelated $(P=0.924)$. The results are shown in Table 4.

\section{Discussion}

To our knowledge, there is no study on the practicability and acceptability of smartphone apps for PD selfmanagement among the elderly. This study investigated the willingness of PD patients (primarily elderly) from various backgrounds to use self-management apps. Although smartphone usage among the elderly is relatively low, they expressed a clear willingness to manage PD 
Table 3 Demographic and clinical characteristics of survey patients who would like to use a Parkinson's disease selfmanagement app, provided it is easy to operate

\begin{tabular}{|c|c|c|c|}
\hline Variable & $S A+A$ & $N+S D+D$ & $P$ \\
\hline Age (years) & $67.05 \pm 9.24$ & $76.14 \pm 9.76$ & $<0.001$ \\
\hline Education level & $10.81 \pm 3.23$ & $8.83 \pm 3.26$ & 0.001 \\
\hline Morisky Scale score & $5.91 \pm 1.41$ & $4.94 \pm 1.39$ & $<0.001$ \\
\hline Gender & & & 0.517 \\
\hline Male/Female & $97 / 72$ & $18 / 17$ & \\
\hline Resident location & & & 0.795 \\
\hline Urban & $143(84.6 \%)$ & $29(82.9 \%)$ & \\
\hline Rural & $26(15.4 \%)$ & $6(17.1 \%)$ & \\
\hline Occupation (employment) & & & 0.478 \\
\hline self-employed & $57(33.7 \%)$ & $14(40.0 \%)$ & \\
\hline Retirees & $112(66.3 \%)$ & $21(60.0 \%)$ & \\
\hline Number of anti-Parkinson drug & & & 0.162 \\
\hline$\leq$ two drugs & $123(72.8 \%)$ & $22(61.1 \%)$ & \\
\hline$\geq$ three drugs & $46(27.2 \%)$ & $14(38.9 \%)$ & \\
\hline Whether browsing a web & & & 0.041 \\
\hline Browsing & $90(53.3 \%)$ & $12(34.3 \%)$ & \\
\hline Not browsing & 79 (46.7\%) & $23(65.7 \%)$ & \\
\hline Parkinson disease course & & & $<0.001$ \\
\hline$\leq 5$ years & $121(71.6 \%)$ & $12(36.4 \%)$ & \\
\hline$\geq 6$ years & $48(28.4 \%)$ & $21(63.6 \%)$ & \\
\hline MDS-UPDRS (H \& Y) & & & 0.013 \\
\hline$\leq 50(1-I I)$ & $87(51.5 \%)$ & $26(74.3 \%)$ & \\
\hline $51-100(I I I)$ & $82(48.5 \%)$ & $9(25.7 \%)$ & \\
\hline
\end{tabular}

through apps. Therefore, using apps for PD selfmanagement is desirable.

In our study, 96.08\% of the participants (196/204) owned mobile phones, and $67.35 \%$ (133/196) owned smartphones [28]. Although many patients use smartphones, few use them to search for information about PD with their phones. Furthermore, mHealth and electronic health (eHealth) apps for selfmanaging chronic diseases are increasingly common [9, 29]. However, most Chinese patients still acquire information about PD by asking doctors in clinics. Few patients with $\mathrm{PD}$ were aware of smartphone apps for self-management before being surveyed [30,

Table 4 Correlation analysis between demographic and clinical characteristics of survey patients and APP acceptance

\begin{tabular}{lll}
\hline & correlation coefficient & $P$ \\
\hline Age & -2.56 & $<0.001$ \\
Education level & 0.167 & 0.017 \\
MDS-UPDRS & 0.007 & 0.924 \\
Parkinson disease course & -2.76 & $<0.001$ \\
\hline
\end{tabular}

31]. In our study, moreover, relatively few PD patients used smartphones compared to the participants with other diseases in a previous study on smartphone use [18]. This may be because smartphones are relatively poorly perceived and accepted by the elderly-a demographic that is particularly vulnerable to PD. Therefore, in terms of Chinese PD patients, the popularity of smartphones needs to be further boosted.

With regards to the content on smartphone apps for PD self-management, patients are eager to gain access to PD education, record their symptoms, and communicate with doctors online through such apps. This reveals a paucity of general PD information, related medical education, and communication with doctors in China. Furthermore, patients indicated the desire to record their motor and non-motor symptoms to better self-manage PD.

The study also found that those patients who were more willing to use self-management PD apps were younger and better educated; they had higher web usage and better drug compliance; and they tended to have more severe PD symptoms for a longer duration. Indeed, younger patients with a higher level of education were more likely to appreciate the opportunities of smart devices. Similarly, patients with experience on the web tended to have a more positive attitude toward appbased self-management. Furthermore, our study found that patients with better drug compliance were more willing to use apps. This is inconsistent with the findings of Browning et al. [26], who suggested that the drug compliance of kidney-transplant patients was not related to their willingness to use apps for self-management. This inconsistency may be the result of the different social context in which the patients were located. The patients in our study were residents of China, and a different social context can result in considerable economic, cultural, and educational differences that affect patient drug compliance. In addition, it is worth mentioning that the drug compliance of the PD patients in this study was generally poor, perhaps because PD patients are older. Moreover, in this study, patients suffering from PD over a longer duration and with more severity indicated a relatively high preference for apps. This is consistent with the results of a previous study involving patients with epilepsy [27], and may be related to the need for a professional platform to obtain advice pertaining to management and control. Generally, the willingness of patients to use apps for PD management is related to age, education level, frequency of web browsing, drug compliance, disease duration, and disease severity. Therefore, app designs should consider these features in target users to improve the practicability and convenience of such apps. 
The study has several limitations. First, all patients with PD were recruited from a single location. In future studies, a larger, more diverse sample should be collected. Second, we investigated patient attitudes toward smartphone apps for PD self-management, without collecting any feedback on the actual use of such apps in practice. In future research, we will assess the effectiveness of apps used to manage PD.

\section{Conclusion}

The results of our study showed that many PD patients owned smartphones, and that there was a positive attitude toward PD-related smartphone apps. Consequently, increasing smartphone usage and developing informative and helpful apps is a promising strategy for PD selfmanagement.

\section{Supplementary information}

Supplementary information accompanies this paper at https://doi.org/10. 1186/s12911-020-01187-x.

\section{Additional file 1 Questionnaire.}

\begin{abstract}
Abbreviations
mHealth: mobile health; eHealth: electronic health; SD: Standard deviation; app: smartphone application; PD: Parkinson's disease; H \& Y: Hoehn \& Yahr Stage; MMAS: Morisky Medication Adherence Scale; MDS-UPDRS: Movement Disorder Society Unified Parkinson's Disease Rating Scale
\end{abstract}

\section{Acknowledgments}

We gratefully acknowledge the assistance of MXL and XC for data collection. And the MMAS-8 Scale, content, name, and trademarks are protected by US copyright and trademark laws. Permission for use of the scale and its coding is required. A license agreement is available from: MMAR, LLC. Donald E. Morisky, ScD, ScM, MSPH, 294 Lindura Ct..Las Vegas, NV USA; dmorisky@gmail. com.

\section{Authors' contributions \\ $J \mathrm{H}$ : study design, data acquisition, statistical analysis, drafting of manuscript, and manuscript revision. DZY: study design, data acquisition, statistical analysis, and significant review of the manuscript. QYZ: statistical analysis and significant review of the manuscript. XFW: data acquisition and interpretation of study findings. XTZ: study design and data acquisition. QHJ: design of this study and data acquisition. HRL: drafting of manuscript and manuscript revision. JL: study design and manuscript revision. JHR: study design, interpretation of study findings, and manuscript revision. JFL: study design, interpretation of study findings, and significant review of the manuscript. All authors reviewed the manuscript for intellectual content, approved the final version, and agreed to be accountable for the work.}

\section{Funding}

The project was funded by the Chongqing Science and Technology Commission (Project No. cstc2015shms-ztzx10009). The funding body has had no influence on the design of the study. The funding body has had no influence on collection, analysis and interpretation of data or on writing of the manuscript.

\section{Availability of data and materials}

The datasets used and analyzed in the study are available from the corresponding author upon reasonable request.

\section{Ethics approval and consent to participate}

Informed consent form was obtained from each study participant, and the study was approved by the Research Ethics Committee of the Second Affiliated Hospital of Chongqing Medical University (No. (2019) No. 268).

\section{Consent for publication}

Not applicable.

\section{Competing interests}

None.

Received: 22 September 2019 Accepted: 13 July 2020

Published online: 11 August 2020

\section{References}

1. Brusse KJ, Zimdars S, Zalewski KR, Steffen TM. Testing functional performance in people with Parkinson disease. Phys Ther. 2005;85(2):134-41.

2. Z Zhang Z-X, Roman GC, Hong Z, Wu C-B, Qu Q-M, Huang J-B, et al. Parkinson's disease in China: prevalence in Beijing, Xian, and Shanghai. Lancet. 2005;365(9459):595-7.

3. Ma CL, Su L, Xie JJ, Long JX, Wu P, Gu L. The prevalence and incidence of Parkinson's disease in China: a systematic review and meta-analysis. J Neural Transm (Vienna). 2014;121(2):123-34.

4. Li G, Ma J, Cui S, He Y, Xiao Q, Liu J, et al. Parkinson's disease in China: a forty-year growing track of bedside work. Transl Neurodegener. 2019;8:22.

5. Sveinbjornsdottir S. The clinical symptoms of Parkinson's disease. J Neurochem. 2016;139(Suppl 1):318-24.

6. O'Sullivan SB. Parkinson's disease. In: O'Sullivan SB, Schmitz TJ, editors. Physical rehabilitation. 5th ed. Philadelphia: F.A. Davis; 2007. p. 853-93.

7. Floch J, Zettl A, Fricke L, Weisser T, Grut L, Vilarinho T, et al. User needs in the development of a health app ecosystem for self-Management of Cystic Fibrosis: user-centered development approach. JMIR mHealth and uHealth. 2018;6(5):e113.

8. Goh G, Tan NC, Malhotra R, Padmanabhan U, Barbier S, Allen JC Jr, et al. Short-term trajectories of use of a caloric-monitoring mobile phone app among patients with type 2 diabetes mellitus in a primary care setting. J Med Internet Res. 2015;17(2):e33.

9. Lorig KR, Holman H. Self-management education: history, definition, outcomes, and mechanisms. Ann Behav Med. 2003;26(1):1-7.

10. McKay FH, Cheng C, Wright A, Shill J, Stephens H, Uccellini M. Evaluating mobile phone applications for health behaviour change: a systematic review. J Telemed Telecare. 2016;24(1):22-30.

11. Nguyen AD, Baysari MT, Kannangara DRW, Tariq A, Lau AYS, Westbrook J, et al. Mobile applications to enhance self-management of gout. Int J Med Inform. 2016;94:67-74.

12. Kumar N, Khunger M, Gupta A, Garg N. A content analysis of smartphonebased applications for hypertension management. J Am Soc Hypertens. 2015;9(2):130-6.

13. Hellqvist C, Dizdar N, Hagell P, Bertero C, Sund Levander M. Improving selfmanagement for persons with Parkinson's disease through education focusing on management of daily life: patients' and relatives' experience of the Swedish National Parkinson School. J Clin Nurs. 2018;27(19-20):3719.

14. Bloem BR, Munneke M. Revolutionising management of chronic disease: the ParkinsonNet approach. Bmj. 2014;348(mar19 9):g1838.

15. Chenoweth L, Gallagher R, Sheriff JN, Donoghue J, Stein-Parbury J. Factors supporting self-management in Parkinson's disease: implications for nursing practice. Int J Older People Nursing. 2008;3(3):187-93.

16. Corpman DW. Mobile health in China: a review of research and programs in medical care, health education, and public health. J Health Commun. 2013; 18(11):1345-67.

17. Whitehead $L$, Seaton $P$. The effectiveness of self-management Mobile phone and tablet apps in Long-term condition management: a systematic review. J Med Internet Res. 2016;18(5):e97.

18. McGillicuddy JW, Weiland AK, Frenzel RM, Mueller M, Brunner-Jackson BM, Taber DJ, et al. Patient attitudes toward mobile phone-based health monitoring: questionnaire study among kidney transplant recipients. J Med Internet Res. 2013;15(1):e6.

19. Jankovic J. Parkinson's disease: clinical features and diagnosis. J Neurol Neurosurg Psychiatry. 2008;79(4):368-76. 
20. Makkos A, Kovacs M, Aschermann Z, Harmat M, Janszky J, Karadi KA-O, et al, Are the MDS-UPDRS-based composite scores clinically applicable? Mov Disord. 2018;33(5):835 1531-8257 (Electronic).

21. Goetz CG, Poewe W, Rascol O, Sampaio C, Stebbins GT, Counsell C, et al. Movement disorder society task force report on the Hoehn and Yahr staging scale: status and recommendations. Mov Disord. 2004;19(9):1020 0885-3185 (Print).

22. Yang A, Wang B, Zhu G, Jiao Z, Fang Y, Tang F, et al. Validation of Chinese version of the Morisky medication adherence scale in patients with epilepsy. Seizure. 2014;23(4):295-9.

23. Berlowitz DR, Foy CG, Kazis LE, Bolin L, Conroy LB, Fitzpatrick P, et al. For the SPRINT study research group. Impact of intensive blood pressure therapy on patient-reported outcomes: outcomes results from the SPRINT study. N Engl J Med. 2017;377:733-44.

24. Morisky DE, Ang A, Krousel-Wood M, Ward HJ. Predictive validity of a medication adherence measure in an outpatient setting. J Clin Hypertens (Greenwich). 2008;10(5):348-54

25. Bress AP, Bellows BK, King J, Hess R, Beddhu S, Zhang Z, et al. Costeffectiveness of intensive versus standard blood pressure control. N Engl J Med. 2017;377:745-55. https://doi.org/10.1056/NEJMsa1616035.

26. Liu X, Wang R, Zhou D, Hong Z. Feasibility and acceptability of smartphone applications for seizure self-management in China: questionnaire study among people with epilepsy. Epilepsy Behav. 2016;55:57-61.

27. Pinnock H, Slack R, Pagliari C, Price D, Sheikh A. Professional and patient attitudes to using mobile phone technology to monitor asthma: questionnaire survey. Prim Care Respir J. 2006;15(4):237-45.

28. Jen W-Y. Mobile healthcare services in school-based health center. Int J Med Inform. 2009;78(6):425-34.

29. Hilliard ME, Hahn A, Ridge AK, Eakin MN, Riekert KA. User preferences and design recommendations for an mHealth app to promote cystic fibrosis self-management. JMIR Mhealth Uhealth. 2014;2(4):e44.

30. Piette JD, Striplin D, Marinec N, Chen J, Trivedi RB, Aron DC, et al. A Mobile health intervention supporting heart failure patients and their informal caregivers: a randomized comparative effectiveness trial. J Med Internet Res. 2015;17(6):e142.

31. Kassam-Adams N, Marsac ML, Kohser KL, Kenardy JA, March S, Winston FK. A new method for assessing content validity in model-based creation and iteration of eHealth interventions. J Med Internet Res. 2015;17(4):e95.

\section{Publisher's Note}

Springer Nature remains neutral with regard to jurisdictional claims in published maps and institutional affiliations.

Ready to submit your research? Choose BMC and benefit from:

- fast, convenient online submission

- thorough peer review by experienced researchers in your field

- rapid publication on acceptance

- support for research data, including large and complex data types

- gold Open Access which fosters wider collaboration and increased citations

- maximum visibility for your research: over $100 \mathrm{M}$ website views per year

At $\mathrm{BMC}$, research is always in progress.

Learn more biomedcentral.com/submissions 